研究課題別評価

1 研究課題名： 認識と演出の相互作用に基づくコミュニケーションロボットの実現

2 研究者氏名: 今井 倫太

\title{
3 研究の狙い
}

本研究の目標は、将来ロボットが公共の場で活動する際のコミュニケーション原理を確立するこ とにある。この目標を達成するために、人間をロボットとのコミュニケーションへと引き込むための 要因の発見および、人間とロボットの出会いを円滑にする手法を実現することを本研究の目的と する。

人間とロボットのコミュニケーションを実現する際に問題となるのは、人間、特に大人が、ロボット が話かける内容に対して真剣に受け答えしないことである。多くの大人は、ロボットの動きや反応 の仕方を観察するのみである。真剣にコミュニケーションが行われている状況では、コミュニケー ションの参加者がお互いに相手が何を意図して発話したのかを、相手の発話内容から推測してい る必要がある。本研究の解決すべき問題点は、ロボットの発話の意図を人間に推測させるように 仕向け、ロボットからの発話に対して人間を真剣に応対させることである。

本研究は、実世界の状態や物体に対して人間が感じる感覚を利用する形でロボットのコミュニケ 一ションを演出し、ロボットの発話の意図を人間が推測するように仕向ける。演出は、次の二つの ステップで構成されている。ステップ1:実世界の状態に人間の注意を向ける、または、物体と相互 作用するように人間を促す。ステップ 2: ステップ 1の演出が成功したときに人間が感じる感覚を言 葉で表現し、人間に話かける。このニつのステップを用いてロボットが持つ感覚を人間に推測させ、 ロボットとのコミュニケーションへと人間を徐々に引き込んで行く。本研究では、演出の効果を被験 者実験により調へ、人間を引き込む要因を明らかにする。さらに、物体や環境に取り付けられたセ ンサネットワークを用いて、自律的に演出を決定するコミュニケーションロボットを実現する。

\section{4 研究成果}

本研究の成果は、被験者実験による演出

の効果の検証および、センサネットワークによる自律的な演出選択の手法に関するものである。 以下に成果毎に説明する。

\section{1 被験者実験による演出の効果の検証}

演出のステップが人間に与える効果について、ロボットの意図を人間が推測するかどうかといっ た観点より検証を行った。実験の説明の前に、この効果で起こる現象について認知モデルで説明 
する。図 1.に演出によるコミュニケーション モデルを示す。図では、人間(図1左)と口 ボット(右)、物体(下)が示されている。人 間は、物体に対して物体の種類、形状、色 など様々な属性を認識する(図中の人間 の中にある Object）。一方で、物体が食べ 物であったら味、花であったら色と香りとい つた形で、物体と相互作用（食べる、飲む、 嗅ぐ、見る)した際にある感覚を感じる(図 中の人間の中にある feeling)。実世界の

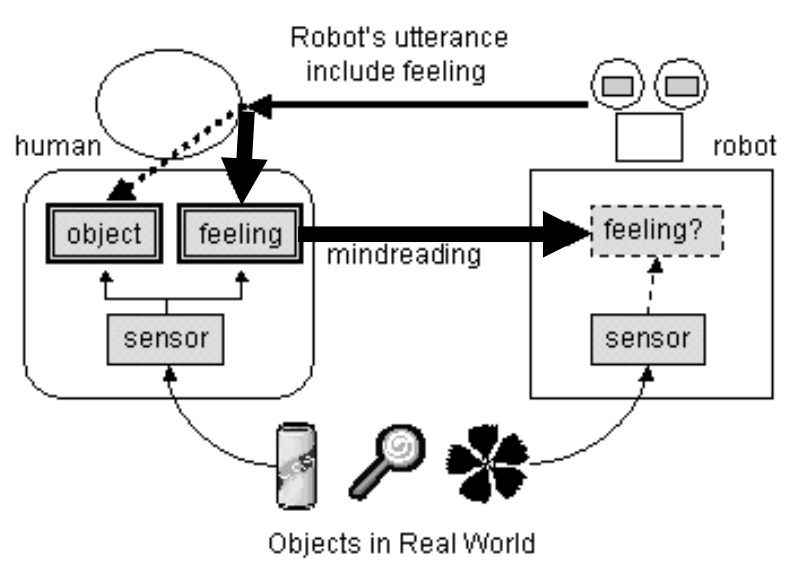

図 1.演出を用いたコミュニケーションモデル
状況への注目や、物体と の相互作用を促すのが演 出のステップ1である。ス テップ2では、感覚を表現 した発話(感覚的発話と以 降呼ぶ）をロボットが行う （図中のロボットから人間 へ伸びる矢印)。この発話 は、実世界の状況や物体 に対して人間が感じている 感覚を表現しているので、 感じている感覚を基にして 発話の解䣋が行われる （図中の人間の頭から feeling へ伸びる矢印)。さ らに、人間は、この結びつ けと同時に、人間と同様の

\section{Experimental Gropu Control Group}

Topic (affective utterance) (informative utterance)

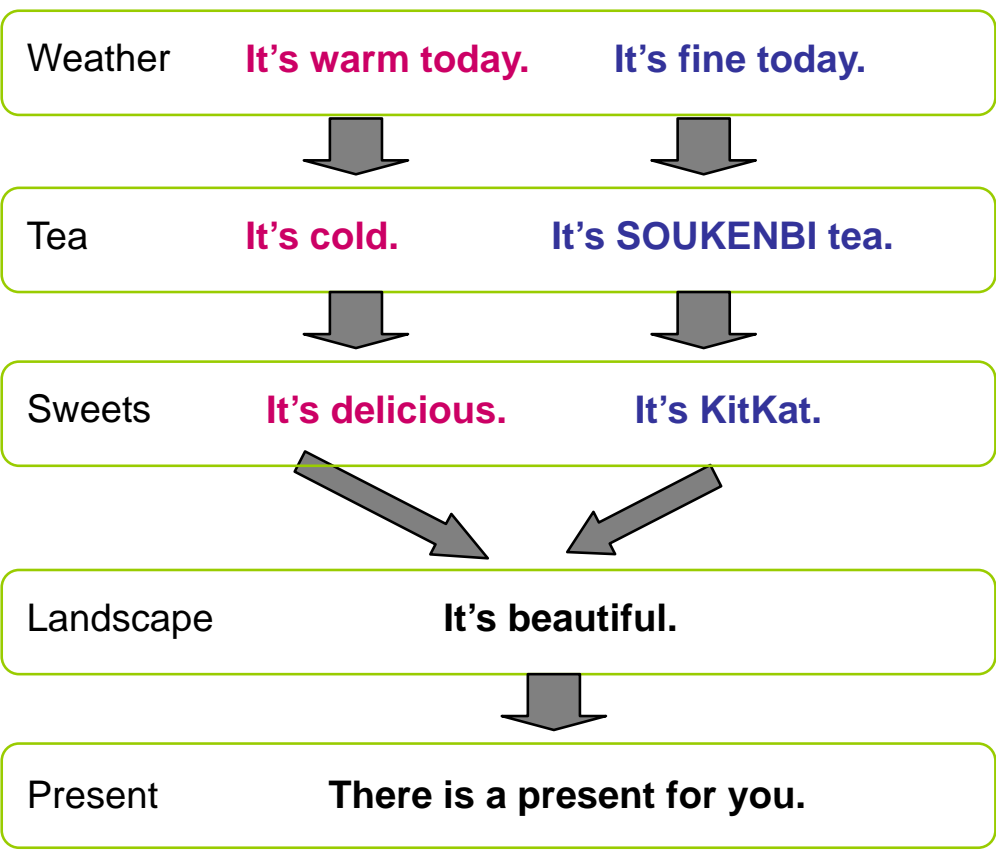

図 2.実験でロボットが用いた発話

感覚をロボットも持つと推測するようになる。演出でこの推測を人間に繰り返させることにより、ロ ボットの発話の意図を推測するように人間を徐々に仕向ける。以上の認知プロセスが、演出で狙 っている効果である。

被験者実験では、演出の効果を検証するために、ステップ 2 に関する違いの対象実験を行った。 比較対象では、ロボットが、感覚を表現した発話の代わりに、情報を伝える発話(情報的発話と以 降呼ぶ)を行う。具体的には、食べ物の名称や、物体に関する解説を行う。情報的発話には、ロボ 
ットの意図を人間に推測させる効果が無いと考えられる。図1の人間の頭から object に伸びてい る点線矢印が示す通り、情報的発話は、 物体の属性と結びつくので、ロボットの 感覚を推測する過程が働かないと考え られる。

実験では、感覚的発話を与えられる 被験者(実験群)と、情報的発話を与え られる被験者(対象群)の二つの群に 男女の被験者 21 を分けた。図 2 に、実 験でロボットが発話した内容を示す。ま た、図 3 に実験環境を示す。発話内容 には、天気とお茶、お菓子、景色、お土 産の話題があり、天気からお菓子まで は実験群と対象群で異なる発話を被 験者に与えた。お菓子とお茶、お土産 は、実際に実験環境に用意されている (図3中のち印)。空は、図3の window の位置である。また、景色とお土産に 関しては、群の違いに関わらず共通の 発話を与えた。そして、感覚的発話の 効果が現れると思われる最後の三つ のトピック(お菓子、景色、お土産)に注 目して人間の行動を観察した。

この実験で検証する仮説は、以下の 物である。

被験者は、ロボットから感覚的発話を 与えられるとロボットの意図を推測す るようになり、ロボットの発話を真剣に 受け止めるようになる。

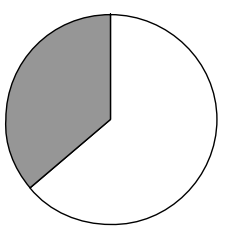

$\operatorname{ExpGrp}(7: 4)$ exit entrance

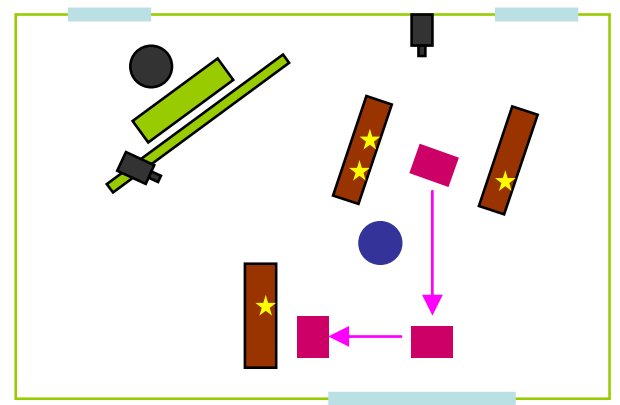

window

図3.実験環境

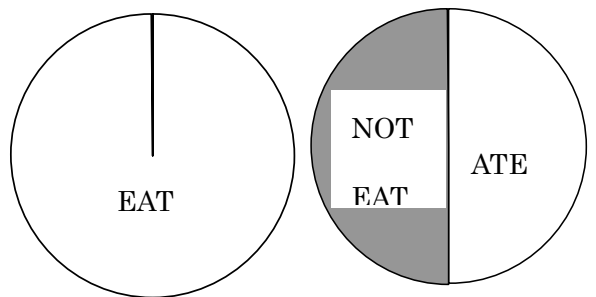

$\operatorname{ExGrp}(11: 0)$

図 4.お菓子を食べた被験者の数

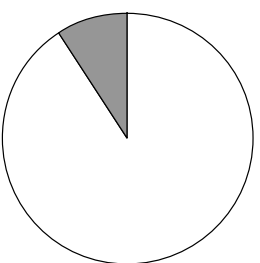

ExpGrp(10:1)

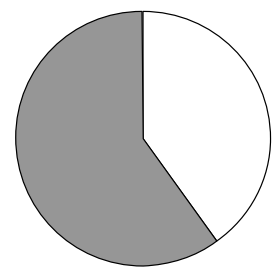

CtrGrp(4:6)

\section{$\square$ Aqree} disaqree

図 5. 景色の発話に同意した被験者の数

Bring the present

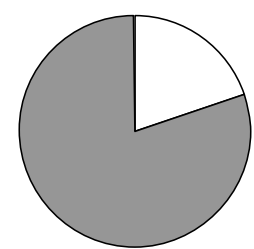

$\operatorname{CtrGrp}(2: 8)$

この仮説から、お菓子·景色·お土産 のトピックで予測できる人間の行動は 図 6. お土産を持って帰った被験者の数 次の通りである。

1) 実験群は、感覚的発話を与えられ続けているので、お菓子を食べて欲しいといったロボットの 
意図を読んでお菓子を食べるが、対象群は食べない。

2) 実験群は、感覚的発話を与えられ続けているので、ロボットの景色に関する発話を真剣に受け 止め同意するが、対象群は同意しない。

3）実験群は、感覚的発話を与えられ続けているので、ロボットからお土産を本気で貪い、お土産 を持って部屋から退出する。一方、対象群は、お土産を部屋に置いて退出する。

図 4 から 6 に実験結果を示す。実験結果は、どれも1)から3)の予測を支持するものであり、ニつ の群の間に有意差があることが確認された。また、お土産を持って帰った被験者から得られたア ンケートによると、お土産を持って帰った理由は、「おみやげだから。」、「せっかくロボットがくれた から。」とロボットの意図を真剣に受け止めていることを示すものであった。一方、持って帰らなか つた被験者は、「実験だから。」「次の実験で使うと思ったから。」と実験を意識しており、ロボットと のコミュニケーションを真剣に捉えていないことが分かった。

以上の実験より、実世界の状態や物体に対して人間が持つ感覚を利用してロボットが感覚的発 話を行うと、人間をロボットとのコミュニケーションへと引き込めることが明らかになった。
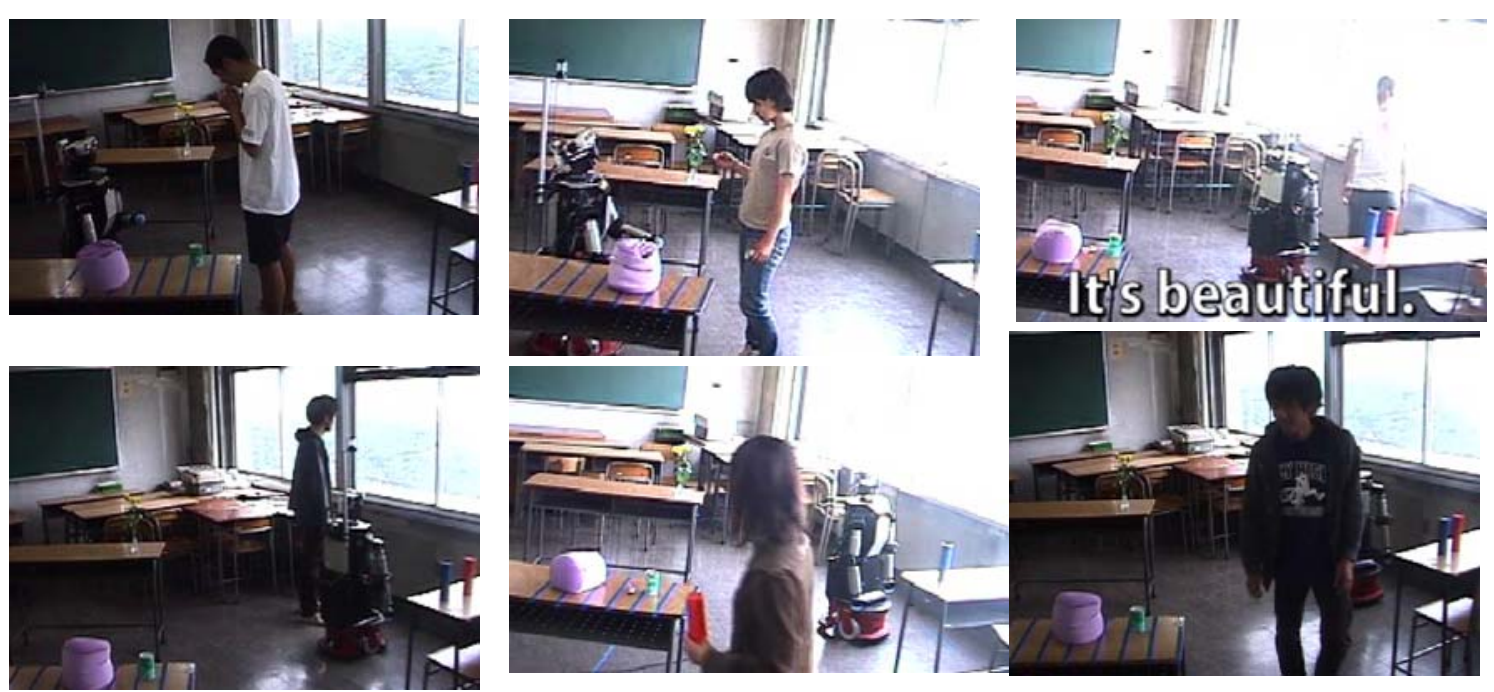

図7.実験シーン: 上段左から右へ、お菓子を食べる実験群の被験者、お菓子を食べ ない対象群の被験者、ロボットに同意する実験群の被験者。下段左から右へ、ロボッ トに同意しない対象群の被験者、お土産を持ってかえる実験群の被験者、お土産を 置いて帰る対象群の被験者。

図7に実験おける被験者の行動を示す。実験シーンからも、実験群の被験者は、ロボットの発話 を真剣に捉え行動していることが見てとれる。一方、対象群の被験者は、ロボットの発話を無視し た行動を行っていることが分かる。 


\section{2 センサネットワークを用いた自律的演出選択}

被験者実験で検証したコミュニケーションモデルをベースに、ロボットとのコミュニケーションへと 人間を引き込む自律的演出選択機構を構築した。図 8 に自律的演出選択機構のシステム構成を 示す。自律的演出選択機構は、無線センサタグが付与された物体の動きに応じて、ロボットの演 出行動を選択する。演出の選択は、システム内の Action module planner で行われる。

自律的演出選択機構の特徵は、センサ情報を解釈するために Context-Chain と呼ばれるモジュ 一ルを持つことである。前節の被験者実験で説明した通り、演出では、実世界のある状態やある 物体に人間を注目させたり、注目対象に関する感覚について言及したりと、文脈を作りながら人 間とコミュニケーションする。文脈が動的に作られ変更されていくので、システムは、文脈に合わ せてセンサ情報の解釈を適宜変更する必要がある。Context-Chain は、Action module planner で 選ばれた演出を元にセンサ情報に最適な解釈を与える。さらに、この解釈は、Action module で の行動選択に用いられ、演出之認識の相互作用が実現されている。

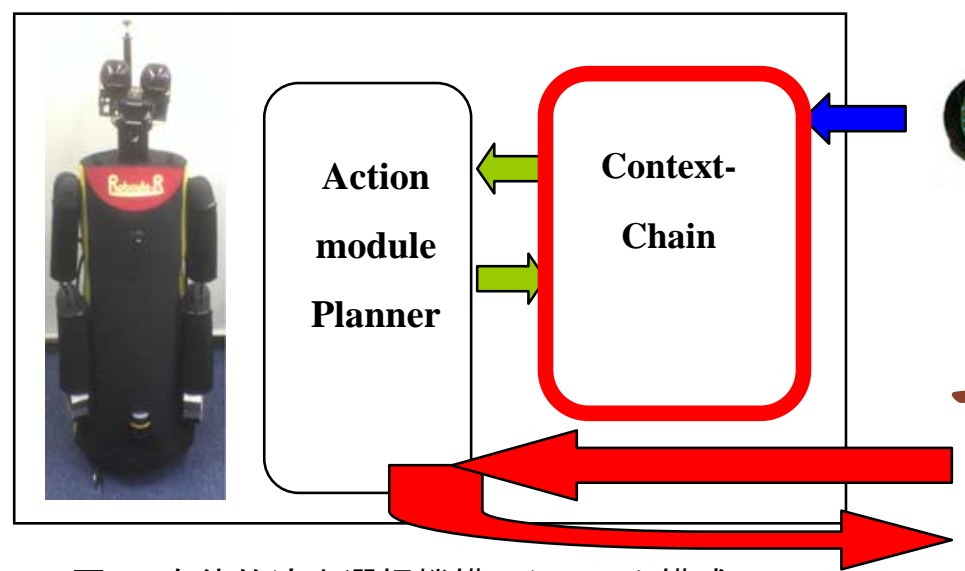

図 8. 自律的演出選択機構のシステム構成
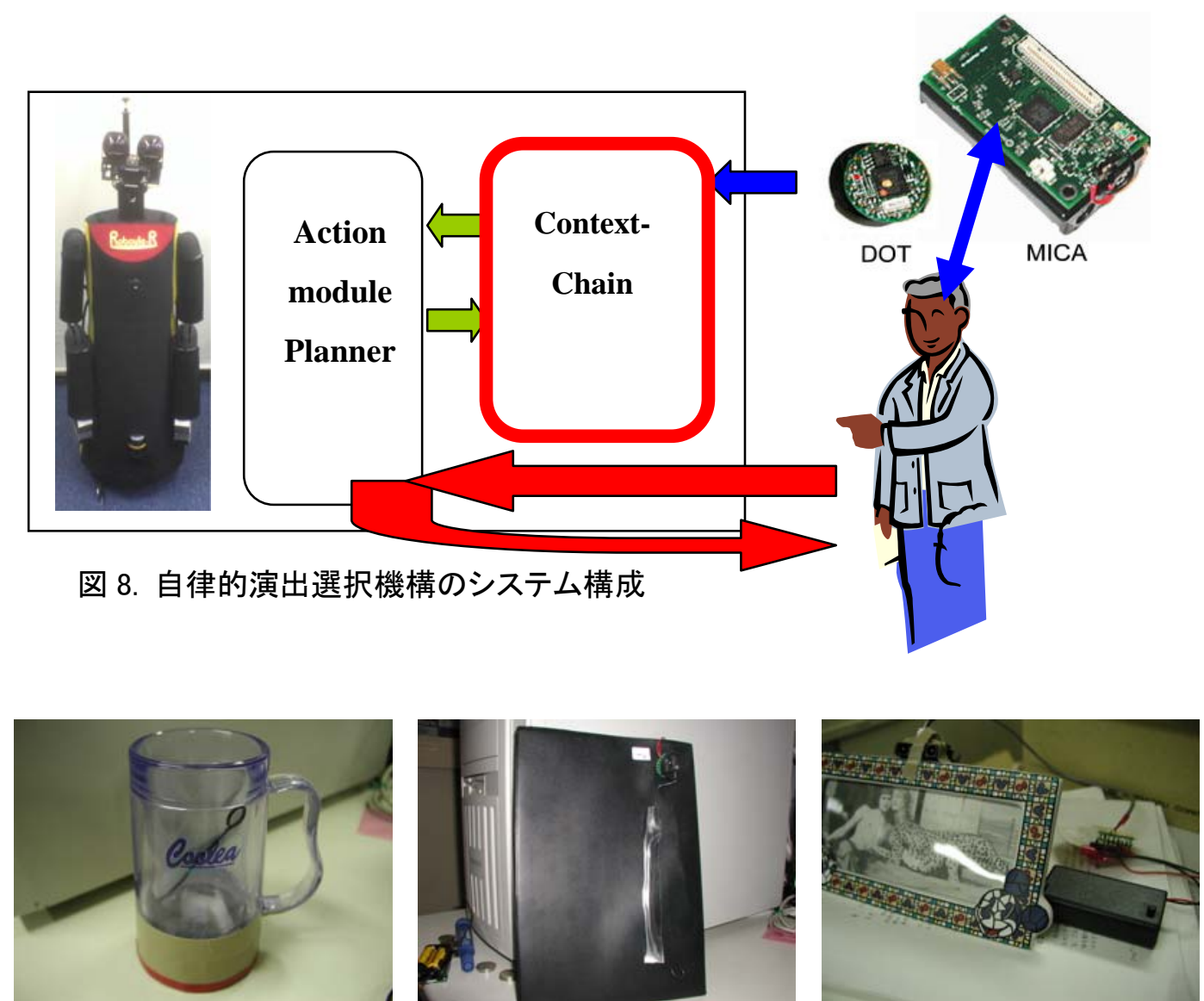

図 9 無線センサノードを付与した物体。左から、加速度センサと光センサが付 いたコップ。加速度センサと曲げセンサが付いた本。人体センサの付いた写真 立て。 


\section{5 自己評価}

当初の研究目標は、関連性理論に基づく形で考案したコミュニケーションモデルの具体化と検 証、そして実際のロボット上にこのモデルを実装することであった。本研究では、物体に対して人 間が持つ感覚を利用する演出手法を考案し、関連性理論に基づくコミュニケーションモデルを具 体化したといえる。さらに、被験者実験によってモデルの効果を実際に検証し、その有効性を確か めることができた。

また、自律的演出選択機構は、センサネットワークを駆使する形でコミュニケーションモデルをロ ボット上に実装した物である。さらに、物体に付与する形で構成されるセンサネットワークは、通常 のセンサネットワークで問題にならなかった、物体の情報とセンサ情報に関する取り扱いという新 たな研究の発展に繋がった。本研究は、当初の目標を達成し、さらに、新たな研究成果となりうる 課題を見いだすことができたと言える。

\section{6 研究総括の見解}

本研究の目標は、将来ロボットが公共の場で活動する際のコミュニケーション原理を確立する ことにある。この目標を達成するために、人間をロボットとのコミュニケーションへと引き込むため の要因の発見および、人間とロボットの出会いを円滑にする手法を実現することが本研究の目的 である。本研究では、物体に対して人間が持つ感覚を利用する演出手法を考案し、関連性理論に 基づくコミュニケーションモデルを具体化したことは、大きな成果であり、高く評価できる。さらに、 被験者実験によってモデルの効果を実際に検証し、その有効性を確かめることができたことも評 価に值する。

今後の展望として、演出によるコミュニケーションとタスクベースのコミュニケーションの融合 および実世界の物体の扱いに特化したセンサネットワークの実現に向け研究を進められたい。

\section{7 主な論文等}

論文

1.川島 英之、遠山 元道、今井 倫太、安西 祐一郎 “リモートメモリを用いたセンサデータストリ 一ムの永続化”情報処理学会論文誌:データベース, Vol.44, No.SIG12(TOD19), pp.98-109, 2003.9

2. 川島 英之、今井 倫太、遠山 元道、安西 祐一郎 "センサデータベースシステム KRAFT の設 計と実装”情報処理学会論文誌:データベース, Vol.45, No.14, pp.39-53, 2004.1

3. 向井 淳、今井 倫太、安西 祐一郎 “観測指向モデルによるロボットの自発的な行動基準の 生成” 知能と情報(日本知能情報ファジイ学会誌), Vol.17, No.3, pp.314-324, 2005.6 


\section{国際会議発表論文}

1. M. Imai, M Narumi, " "Generating Common Quality of Sense by Directed Interaction," 12th IEEE Workshop Robot and Human Interactive Communication (Ro-MAN2003), pp.199-204, (2003-10, Millbrae)

2. M Narumi, M. Imai, "Human-Centric Approach for Human-Robot Interaction," The 8th Pacific Rim International Conference on Artificial Intelligence (PRICAI2004), pp.993--994, (2004-8).

3. M. Imai, M Narumi, "Robot Behavior for encouraging immersion in interaction," Complex Systems Intelligence and Modern Technological Applications (CSIMTA04), pp.425-430, (2004-9, Cherbourg).

4. M. Imai, M. Narumi "Immersion in Interaction Based on Physical World Object" The 2005 International Conference on Active Medial Technology (AMT2005), pp.523-528, 2005.5

5. M. Imai, H. Osawa, M. Narumi "Designing Human-Robot Interaction via Physical World Objects" IEEE Workshop on Advanced Robotics and Its Social Impacts (ARSO' 05), CDROM, 2005.6

\section{国内会議発表論文}

1. 鳴海真里子、今井倫太 “演出を用いた実世界情報の顕在化の研究”第 17 回人工知能学会 全国大会, CD-ROM 版 1D1-01, 2003.6

2. 鳴海真里子、今井倫太 "演出を用いたヒューマン・ロボット・インタラクション" 合同エージェント ワークショップ\&シンポジウム 2003 (JAWS2003) 講演論文集, pp.438-445, 2003.10

3. 鳴海真里子、今井倫太 “共感に基づく人間とロボットのインタラクション” 日本認知科学会第 21 回大会, pp.12-13, 2004.7

4. 今井倫太、鳴海真里子 "ロボットとのコミュニケーションへの没入を実現するコミュニケーション 技術” 情報処理学会研究報告、CVIM-146, Vol.8, pp.17-22, 2004.11

5. 大澤博隆、向井淳、今井倫太 "SOBAR:コミュニケーションロボットによる環境センサ情報への 制約"人工知能学会第 19 回全国大会論文集, 2005.6

\section{総説·解説}

1. 今井 倫太 “コミュニケーションロボットの実現に向けて”, KAST Report, Vol.15 , No. 2, pp.10-17, 2003.

2. 今井倫太、安西祐一郎 “人間とロボットのインタラクション”, 学術月報、第 57 巻、 9 号、2004 年 9月号, pp.798-805, 2004.

3. 今井 倫太” 生活支援型ロボットの最近の技術動向”, 情報通信 Bulletin, No. 026, pp.1-5, 2005. 
特許出願

1. 今井 倫太” コミュニケーションロボットシステム”, 特願 2005-052308, 2005

\section{招待講演}

1. 人間とロボットのコミュニケーションの実現に向けて, 相模原市立博物館日曜講演会 2004

2. ロボットが変わる一カから心へ一, 第13回 慶應義塾大学理工学部 市民講座にて講演, 2004

3. コミュニケーションロボットの現状と課題, 川崎市テクのトランスファー, 2005 